\title{
Effect of growth conditions and extraction solvents on enhancement of antimicrobial activity of the microalgae Chlorella vulgaris
}

\author{
Ahmad Mashhadinejad ${ }^{1}$, Hojjatolah Zamani $^{{ }^{*}}$, Jannat Sarmad ${ }^{1}$ \\ ${ }^{1}$ Department of Biology, Faculty of Science, University of Guilan, Rasht, Iran \\ Received: Jan 23, 2017, Revised: Jan 30, 2017, Accepted: Feb 8, 2017
}

\begin{abstract}
Regarding increasing rate of drug resistance among microbial pathogens, a global search to find new antimicrobial agents from natural compounds with fewer side effects has been considered by many researchers worldwide. Bioactive compounds with good antimicrobial activity have been isolated from different algae and cyanobacteria. The current study was performed to determine antimicrobial potential and to characterize the effect of algal growth modes (autotrophic, heterotrophic and mixotrophic) and extraction solvents on antimicrobial activity of the microalgae Chlorella vulgaris against four bacterial and one fungal pathogens. $C$. vulgaris was grown under different growth conditions and the biomass was harvested. Different extracts were prepared using acetone, chloroform and ethyl acetate as extraction solvents and antimicrobial activity of the extracts was investigated against two Gram positive bacteria (Bacillus subtilis and Staphylococcus aureus), two Gram negative bacteria (Escherichia coli and Pseudomonas aeruginosa) and a fungal strain (Candida albicans) using agar well diffusion assay. In addition, Minimal Inhibitory Concentration (MIC) of the extracts were determined. Moreover, the total oil content and lipid productivity of $C$. vulgaris grown under different modes were determined. The heterotrophic growth resulted in stronger antimicrobial activity compared to the other growth conditions. In addition, the highest antimicrobial activity was observed for chloroform mediated extract and extraction using acetone resulted in minimum antimicrobial activity. Moreover, heterotrophic and mixotrophic growth significantly increased the total lipid content and lipid productivity compared to the autotrophic growth. $C$. vulgaris exhibited good antimicrobial potential and the antimicrobial efficacy could be influenced by extraction solvents and growth conditions.
\end{abstract}

Keywords: Antimicrobial activity, Chlorella vulgaris, chloroform extract, microalgae, growth modes

Pharm Biomed Res 2016; 2(4): 65-73

\section{Introduction}

Owing to the alarming increase of drug resistance among microbial pathogens, many efforts have been made to discover and characterize new antimicrobial agents $(1,2)$. Aquatic organisms including bacteria, algae, sponges, aquatic weeds, etc. produce a large number of bioactive compounds with antimicrobial, anticancer and antioxidant activity. The organisms produce these compounds to protect themselves against biotic and abiotic factors (3).

Algae comprise of a heterogeneous group of organisms which are divided into microalgae and macroalgae, based on their size. These organisms produce a high variety of secondary metabolites in order to adapt themselves to the environmental conditions and/or to protect against predation, herbivory and to compete for space (4). In this regard, various materials such as amino acids, terpenoids, phlorotannins, alkanes, halogenated ketones, steroid compounds, cyclic polysulfides, fatty acids, acrylic acid, phenols, etc. are obtained from algae, some of which have good antimicrobial activity and could be employed as pharmaceutical agents $(5,6)$.

According to the source of carbon, microalgae can be classified as autotrophs, mixotrophs and heterotrophs. Autotrophic microalgae require only inorganic compounds such as $\mathrm{CO}_{2}$ as a carbon source while, heterotrophic microalgae cannot fix carbon and use organic carbon for growth. Some photosynthetic 
microalgae are recognized as mixotrophs which have both autotrophic and heterotrophic growth $(7,8)$. Chlorella is a marine microalgae able to grow in all the above conditions (9). Medicinal properties of Chlorella $s p$. such as antibacterial, antifungal and anti-cancer has been reported previously (10-12). Antibacterial activity of Chlorella was first documented in 1944 and was reported to be associated with a mixture of $\mathrm{C}_{18}$ fatty acids named 'chlorellin'(10).

Production rate and type of bioactive compounds produced by microalgae could be influenced by growth condition which may affect antimicrobial activity of the algal extract. Thus, this study aimed to investigate the possible effect of different growth modes on antimicrobial activity of the microalgae Chlorella vulgaris. Simultaneously, the effect of different extraction solvents including acetone, chloroform and ethyl acetate on antimicrobial potential of $C$. vulgaris was determined.

\section{Materials and method}

\section{Sample purification and preliminary culture}

C. vulgaris was obtained from the Sturgeon Research Institute, Rasht city, Iran. The alga was washed several times and cultivated in Zinder $(\mathrm{Z}-8+\mathrm{N})$ solid medium. Then, repeated cultivation in Zinder broth $(\mathrm{pH} 7)$ was performed and the axenic algal culture was obtained. The Zinder medium contained $(\mathrm{g} / \mathrm{l}): 1, \mathrm{NaNO}_{3} ; 0.19$, $\mathrm{H}_{3} \mathrm{BO}_{3} ; 0.625 \mathrm{Ca}\left(\mathrm{No}_{3}\right)_{2} .4 \mathrm{H}_{2} \mathrm{O} ; 0.5, \mathrm{Mg}\left(\mathrm{SO}_{4}\right) .7 \mathrm{H}_{2} \mathrm{O}$; $0.075, \mathrm{KH}_{2} \mathrm{PO}_{4} ; 0.1, \mathrm{Na}_{2} \mathrm{CO}_{3} ; 0.005, \mathrm{FeCl}_{3} .6 \mathrm{H}_{2} \mathrm{O} ; 0.01$, EDTA.Na $;$; 0.03, $\mathrm{KBr} ; 0.008$, $\left(\mathrm{NH}_{4}\right)_{6} \mathrm{MO}_{7} \mathrm{O}_{24} .4 \mathrm{H}_{2} \mathrm{O}$; $0.001, \mathrm{MnCl}_{2} .4 \mathrm{H}_{2} \mathrm{O} ; 0.001, \mathrm{Na}_{2} \mathrm{SiO}_{3} .9 \mathrm{H}_{2} \mathrm{O} ; 0.008$, $\mathrm{Ca}\left(\mathrm{SO}_{4}\right) .5 \mathrm{H}_{2} \mathrm{O} ; 0.5, \mathrm{AL}_{2}\left(\mathrm{SO}_{4}\right)_{3} .18 \mathrm{H}_{2} \mathrm{O} ; 0.03$, KI. In order to solidify, $1.5 \%$ agar was added to the culture medium prior to autoclaving (13). In order to prepare the starter culture, the algal cells were inoculated at $10 \%$ (v/v) into Zinder broth medium at $25{ }^{\circ} \mathrm{C}$, under a 2500 lux light intensity with a 12:12 $\mathrm{h}$ light period for seven days.

\section{Growth conditions}

The batch cultivation of the microalgae was performed by inoculating $10 \%$ of starter culture into $250 \mathrm{~mL}$ Zinder medium in a $500 \mathrm{~mL}$ flask. The incubation was performed at $30{ }^{\circ} \mathrm{C}$ and the cultures were air-aerated with a flow rate of $0.01 \mathrm{ml} / \mathrm{min}$. For photoautotrophic cultivation, the cultures were illuminated with a 2500 lux light intensity with a 12:12 h light photoperiod. For mixotrophic and heterotrophic cultivation, glucose (12 $\mathrm{g} / \mathrm{l})$ and glycerol $(4.0 \mathrm{~g} / \mathrm{l})$ were used as carbon sources with and without light illumination, respectively. All flasks were shaken at $150 \mathrm{rpm}$.

\section{Extraction}

At the end of log phase, algal cells from different growth modes were harvested using centrifugation at $3000 \mathrm{~g}$ for $5 \mathrm{~min}$. The pellets were washed twice with distilled water and dried at $70{ }^{\circ} \mathrm{C}$ in a vacuum oven until a constant weight was obtained. Extraction was performed using the solvents of different polarity: acetone, ethyl acetate and chloroform. Five grams of the algal powders from different cultures were suspended in the solvents at the ratio of $6: 1(\mathrm{v} / \mathrm{w})$, left at room temperature for $48 \mathrm{~h}$ and then, were sonicated (24 $\mathrm{KHz} / 240 \mathrm{~W}$ ) for $15 \mathrm{~min}$ (Misonix Sonicator 3000). Finally, the suspensions were centrifuged at $3000 \mathrm{~g}$ for $10 \mathrm{~min}$ and the supernatants were filtered and concentrated. The extracts were kept in dark at $4{ }^{\circ} \mathrm{C}$ until use.

\section{Microbial strains}

Antimicrobial activity of algal extracts against microbial pathogens including two Gram positive bacteria (Staphylococcus aureus ATCC 6538; Bacillus subtilis ATCC 6051), two Gram negative bacteria (Escherichia coli ATCC 8739; Pseudomonas aeruginosa ATCC 9027) and one fungal strain (Candida albicans ATCC 10231) were investigated.

\section{Antimicrobial activity of algal extracts}

Antimicrobial activity of different algal extracts against microbial pathogens was investigated using agar welldiffusion assay. Briefly, fresh cultures of microbial strain were prepared and a suspension of each microorganism with the approximate cell populations of $1.5 \times 10^{8} \mathrm{CFU} / \mathrm{ml}$ was prepared in distilled water. Microbial strains were inoculated uniformly onto the surface of Muller-Hinton Agar (bacteria) and Sabouraud Dextrose Agar (fungus) using sterile cotton swabs. Wells of approximately $6 \mathrm{~mm}$ in diameter were bored using a well cutter and $50 \mu \mathrm{L}$ of algal extracts were added to the wells. The plates were incubated at $37^{\circ} \mathrm{C}$ for 24 and $72 \mathrm{~h}$ for bacterial and fungal strains, respectively. The assay was performed in triplicates and 
the diameter of zones of inhibition (ZOI) formed around the wells were determined. The extraction solvents were used as negative controls and disks with anti-bacterial agent Gentamycin $(10 \mu \mathrm{g})$ or antifungal agent Nystatin (100 IU) were used as positive controls (14).

\section{Minimal inhibitory concentration (MIC)}

The minimal inhibitory concentration (MIC) was determined for algal extracts using the broth microdilution method to give a concentration between 160 and $5 \mathrm{mg} / \mathrm{ml}$ (15). Briefly, a gradient of each extract was prepared in 96-well microtiter plates and inoculated with $100 \mu \mathrm{L}$ of microbial suspensions. In order to prepare microbial inocula, fresh microbial cultures were suspended in Muller Hinton broth for bacteria and Sabouraud Dextrose Broth for the fungus strain. The final microbial cells concentration was adjusted to $5 \times 10^{5} \mathrm{CFU} / \mathrm{ml}$. MIC was determined as the lowest extract concentration that prevents visible bacterial growth after 24 and $72 \mathrm{~h}$ of incubation at $37{ }^{\circ} \mathrm{C}$ for the bacteria and fungus, respectively. Appropriate controls of medium with microorganisms or each extract were included. The assay was performed in triplicates for each microorganism and the final results were presented as the arithmetic average.

\section{Extraction and determination of lipids}

Algal cells were harvested by centrifugation as described above and the pellets were washed with distilled water and dried. Fifty $\mathrm{mg}$ of dried algal biomass was taken in $15 \mathrm{~mL}$ of test tube, $1.6 \mathrm{~mL}$ of double distilled water, $4 \mathrm{~mL}$ methanol and $2 \mathrm{~mL}$ of chloroform were added and mixed thoroughly for 30 s.Then, an additional $2 \mathrm{~mL}$ of chloroform and $2 \mathrm{~mL}$ of double distilled water were added and the solution was mixed for $30 \mathrm{~s}$. Following this, the mixture was centrifuged, at $2000 \times \mathrm{g}$ for $10 \mathrm{~min}$ and the upper layer was decanted and the lower chloroform layer containing the extracted lipids was collected in another test tube. The extraction procedure was repeated again with the residual pellet and both the chloroform extracts were mixed together and evaporated till it gets dried. The dried total lipids were measured gravimetrically and lipid content was calculated as dry mass percentage (16). In addition, the lipid productivity [PL(mg/(l.day)]) was calculated according to the: Eq. (1) (17).
Lipid productivity $=$

biomass productivity $\left(\mathrm{mg} \mathrm{L}^{-1} \cdot \mathrm{d}^{-1}\right) \times \frac{\text { lipid content }}{100}$ (1)

\section{Statistical analysis}

SPSS 18.0 software was used for statistical analysis. Difference in the antimicrobial activity of different extracts against each microbial strain was evaluated using the one-way ANOVA and a $\mathrm{P}$ value of 0.05 was considered as statistically significant.

\section{Results}

Screening of antimicrobial activity under different growth modes

Antimicrobial activity of $C$. vulgaris grown under different modes was investigated using agar welldiffusion method. According to the results, the diameter of Zone of Inhibition (ZOI) depended on the growth modes, type of solvents and the tested microbial strain. Overall, almost all $C$. vulgaris extracts showed antibacterial activity regardless of the growth modes and the extraction solvents. However, there was differences in the antimicrobial potential of the algal extracts. Generally, $C$. vulgaris grown under heterotrophic condition showed higher antimicrobial activity specially against Gram negative and the fungal strain, while the lowest antimicrobial activity was observed for the alga grown under autotrophic condition. Compared to the autotrophic mode, mixotrophic growth of $C$. vulgaris increased its antibacterial activity against two Gram positive bacteria, S. aureus and B. subtilis, while, heterotrophic growth showed better antimicrobial activity against the Gram negative bacteria (E. coli and $P$. aeruginos $a$ ) and the fungal pathogen $C$. albicans. However, there was not a significant difference in antibacterial and antifungal potential of $C$. vulgaris grown under heterotrophic and mixotrophic conditions. Moreover, the least antibacterial and antifungal activity was observed when the algal extract from autotrophic condition was evaluated.

B. subtilis and $S$. aureus were the most susceptible bacteria with the ZOI of 23 and $22 \mathrm{~mm}$ when exposed to the chloroform and ethyl acetate extracts from mixotrophic culture, respectively. The highest microbial resistance to algal extract was observed for both Gram 
negative bacteria with ZOI of $6 \mathrm{~mm}$ when exposed to acetone mediated extract from autotrophic culture. ZOI for the standard antibiotics were in range of 14 to 24 $\mathrm{mm} /$ disk. The antimicrobial activity of $C$. vulgaris grown under different growth conditions was presented in Figure 1.

According to our results, extraction using chloroform resulted in the highest antimicrobial activity against the microbial pathogens. The only exception was observed for the ethyl acetate mediated extract from mixotrophic culture which showed higher antibacterial activity against $S$. aureus. In addition, acetone mediated extracts showed lower antimicrobial potential compared to the other solvents.

\section{MIC values of algal extracts}

In addition, the MIC of the extracts from $C$. vulgaris grown under different conditions was determined. The MIC of $C$. vulgaris against microbial pathogens ranged from $10-160 \mathrm{mg} / \mathrm{ml}$, depending on the growth modes and the extraction solvents. Heterotrophic growth reduced the MIC values of $C$. vulgaris extracts against microorganisms while, mixotrophic and autotrophic growth resulted in moderate and high MIC values, respectively. Among the microbial pathogens, the highest susceptibility was observed for $B$. subtilis (MIC $=10 \mathrm{mg} / \mathrm{ml}$ ) and $S$. aureus $(\mathrm{MIC}=20 \mathrm{mg} / \mathrm{ml}$ ) to the algal extract from heterotrophic culture while, the highest resistance was recorded for E. coli $(\mathrm{MIC}=160)$ and $P$. aeruginosa $(\mathrm{MIC}=160)$ to the extracts from autotrophic growth.

The chloroform extracts were more potent than other extracts against the majority of tested microbial strains and showed lower MIC values. The least MIC value was recorded for the chloroform extract against $B$. subtilis (MIC $=10 \mathrm{mg} / \mathrm{ml}$ ) while, the acetone mediated extracts showed high MIC values, especially against Gram negative bacteria (MIC $\geq 40 \mathrm{mg} / \mathrm{ml}$ ). The MIC values of different algal extracts against microbial pathogens were presented in Table 1 .

\section{Lipid content and productivity}

As summarized in Fig. 2, different culture conditions resulted in significant difference in the lipid content and productivity of $C$. vulgaris. The lowest lipid content, based on the dry cell mass, was $32.13 \%$ which was obtained in the autotrophic culture, and the highest value of $56.16 \%$ was obtained when the alga was cultured in heterotrophic condition that was significantly different compared to the control $(\mathrm{p}<$ $0.05)$.The differences in lipid volumetric productivity caused by the effects of glucose/glycerol (12:4 g/l.) addition was more expressed than in the lipid content. Supplementation with organic substances stimulated the lipid volumetric productivity of $C$. vulgaris. The maximum lipid productivity ( $83.56 \mathrm{mg} /($ (lday)) was achieved when $C$. vulgaris was cultured in heterotrophic condition, which was 29.01 times higher than the autotrophic mode.

\section{Discussion}

Physical and chemical conditions of culture media affect the biochemical compositions in algal cultures. Several studies were performed on the effects caused by changes in levels of specific elements, culture time, temperature, $\mathrm{pH}$ and culture model $(18,19)$. It is possible to manipulate the culture condition to enhance biological activities of microalgae. In the current study, the possible effects of growth conditions and extraction solvents on antimicrobial potential of $C$. vulgaris was determined. In the last few decades, researchers have recognized the increasing importance and value of microalgae as a potential source of novel antimicrobial agents (20, 21). Several studies documented antibacterial activity of Chlorella species (22-24). However, few attempts to manipulate the antimicrobial activity based on the culture conditions were performed.

Chlorella sp. can adapt to different growth conditions such as phototrophic, heterotrophic and mixotrophic cultivation $(9,25)$, and some reports have indicated that the lipid content and productivity could be greatly dependent on those conditions $(9,26,27)$. In the current study C. vulgaris showed different levels of antimicrobial activity under autotrophic, heterotrophic and mixotrophic growth. According to our results, oil content and productivity of $C$. vulgaries grown under different modes varied. In a Previous study, heterotrophic and mixotrophic growth increased the lipid content and oil productivity of $C$. vulgaris which was similar to our finding (28). 

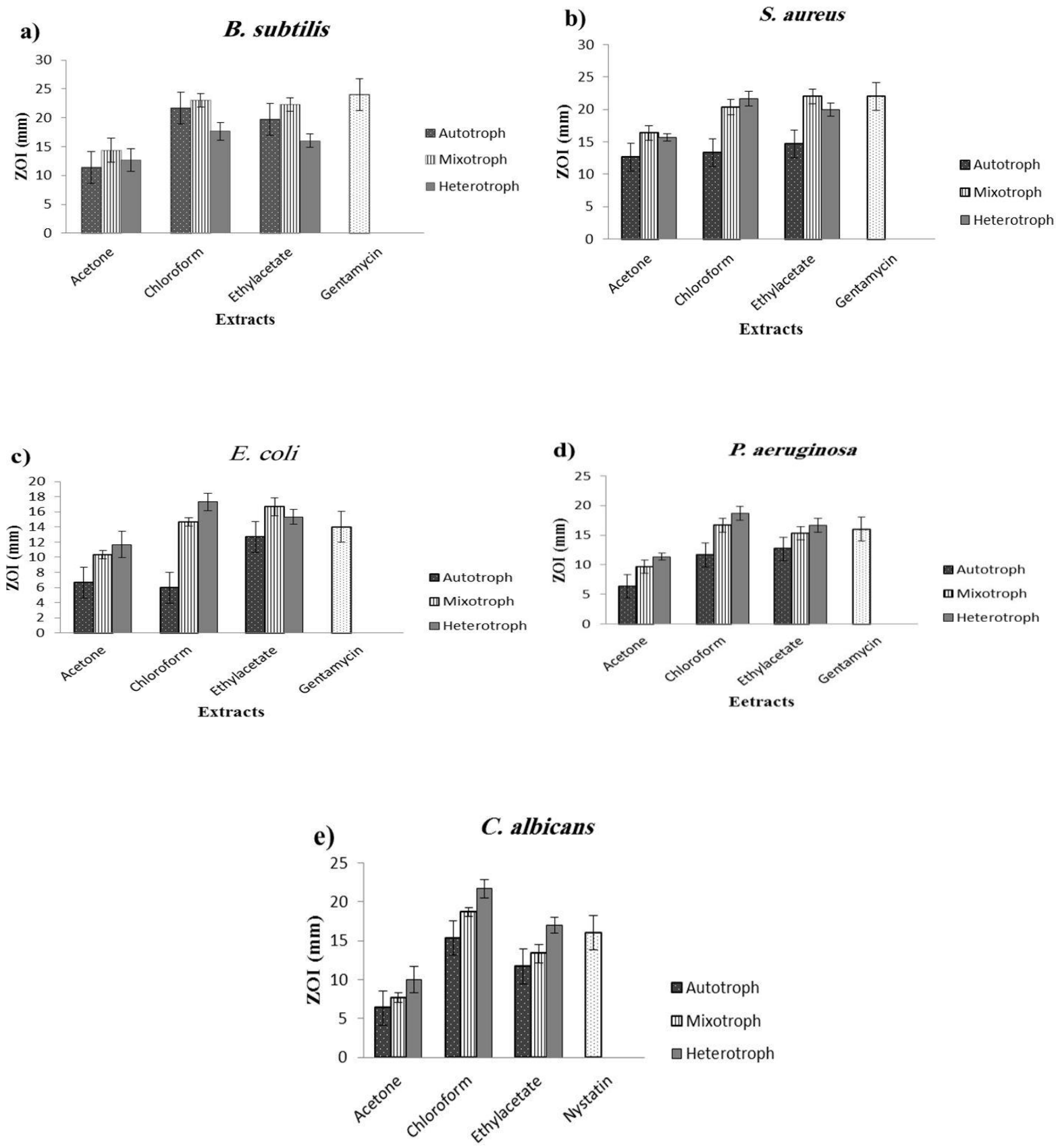

Eetracts

Figure 1 Zone of Inhibition (ZOI) of different extracts from C. vulgaris and the control antibiotics (nystatin $_{(100 \mathrm{IU} / \mathrm{disk})}$ and Gentamycin $\left.{ }_{(10 \mu \mathrm{g} / \mathrm{disk})}\right)$ against microbial pathogens 
Table 1 The MIC values of different extracts of C. vulgaris

\begin{tabular}{r|ccc|ccc|ccc}
\cline { 2 - 9 } Microorganisms & \multicolumn{3}{|c|}{ Autotrophic } & \multicolumn{3}{c|}{ Heterotrophic } & \multicolumn{3}{c}{ Mixotrophic } \\
\cline { 2 - 10 } & Acetone & Chloroform & $\begin{array}{c}\text { Ethyl } \\
\text { acetate }\end{array}$ & Acetone & Chloroform & $\begin{array}{c}\text { Ethyl } \\
\text { acetate }\end{array}$ & Acetone & Chloroform & $\begin{array}{c}\text { Ethyl } \\
\text { acetate }\end{array}$ \\
\cline { 2 - 10 } B. subtilis & 40 & 10 & 20 & 20 & 10 & 10 & 40 & 20 & 20 \\
S. aureus & 80 & 80 & 80 & 40 & 20 & 10 & 40 & 20 & 20 \\
E. coli & 160 & 160 & 80 & 80 & 80 & 80 & 80 & 80 & 80 \\
P. aeruginosa & 160 & 80 & 80 & 80 & 80 & 80 & 80 & 80 & 80 \\
C. albicans & 160 & 80 & 80 & 80 & 40 & 40 & 160 & 80 & 80 \\
\hline
\end{tabular}

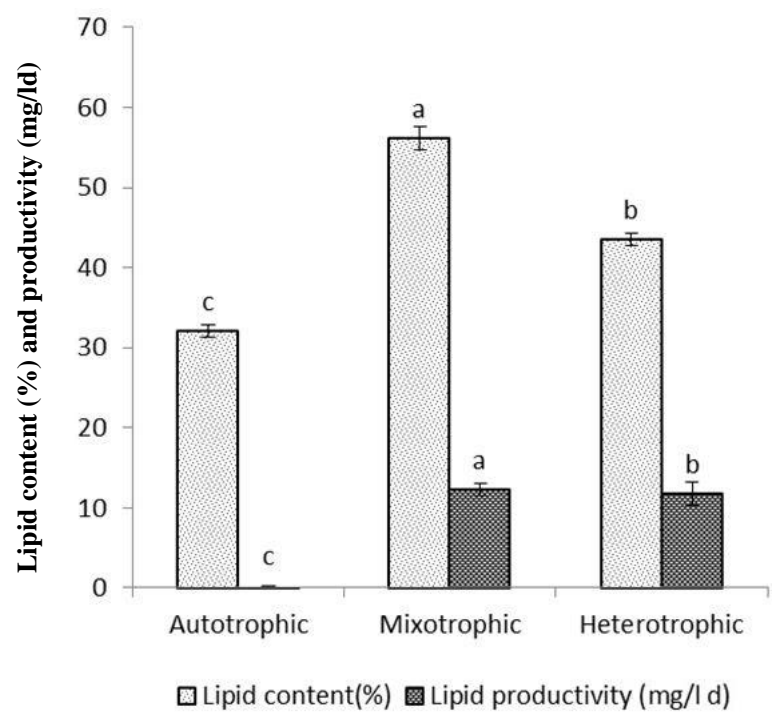

Figure 2 Effect of different growth modes on the lipid content and productivity of $C$. vulgaris. Values are mean \pm S.D., $N=3$; the significance of differences is denoted by different letters $(\mathrm{p}<$ $0.05)$

Oil productivity is defined as the oil produced by the algae per day per liter of culture, which is dependent on both growth rate and lipid content.

Increased antimicrobial activity of $C$. vulgaris grown under heterotrophic and mixotrophic modes could be associated to higher lipid productivity under mentioned conditions. Biochemical composition in the $C$. vulgaris culture has been documented to be variable under different growth conditions. In addition, Liang et al., (9) reported that heterotrophic and mixotrophic growth of C. vulgaris increased total lipid production which was in accordance with our results. Moreover, it has been reported that heterotrophic and mixotrophic growth could increase production of some unsaturated fatty acids and algal pigments $(9,27,28)$.

Mixtures of polyunsaturated and saturated fatty acids produced by microalgae are identified as antimicrobial agents especially towards Gram-positive bacteria. Thus, the higher susceptibility of Gram positive bacteria in our study could be attributed to the unsaturated fatty acids produced by $C$. vulgaris. Recently, long-chain unsaturated fatty acids and hydroxylated derivatives 
such as 15-hydroxyeicosapentaenoic acid and 15hydroxyeicosatrienoic acid with inhibitor activity to Methicillin resistant S. aureus (MRSA) were discussed as potential agents in treatment of multidrug resistant infections (29). In an study it was found that Hexadecanoic acid (16:0) was the most abundant fatty acid component in the autotrophic growth of $C$. vulgaris, while octadecadienoic acid (C18:2) was the largest portion for the heterotrophic and mixotrophic growth. Increased antimicrobial microbial activity of $C$. vulgaris from heterotrophic and mixotrophic cultures could be attributed to the higher biosynthesis of unsaturated fatty acids. Although the exact mechanism of action for the algal fatty acids in not well understood, damage to the cell membrane seems to be the most probable mechanism. Algal fatty acids could penetrate to the microbial cell membrane and cause membrane damage and eventually cell death (29).

In addition to the fatty acids, it has been suggested that antimicrobial activity of $C$. vulgaris could be attributed to its proteins, vitamins, carotenoids and phenolic compounds $(30,31)$. The antifungal activity of the algal culture filtrates has been attributed to the presence of bioactive compounds such as phenolic compounds, saponins and alkaloids in the algal culture filtrates (32). Many researchers reported higher algal biomass production under heterotrophic and mixotrophic culture $(27,28)$. Thus, the higher antimicrobial activity under these conditions may be due to the higher production of the mentioned molecules as well.

In our study, Gram positive bacteria showed higher susceptibility to the algal extract. This finding was similar to the previous studies. Bhagavathy et al., reported higher susceptibility of Gram positive bacteria against different extracts from a green algae Chlorococcum humicola (33). In addition, higher susceptibility of Gram positive bacteria to algal extracts was reported by Prashantkumar et al., (21). The higher susceptibility of Gram positive bacteria to the algal extracts could be attributed to the difference of Gram positive and Gram negative bacterial cell envelope. In Gram positive bacteria, bacterial cells are surrounded by only one lipid membrane named cytoplasmic membrane and peptidoglycan. In contrast, Gram negative bacteria have two lipid membranes which protects them against antimicrobial agents and may cause higher resistance of bacterial cells to the algal extracts. Lack of additional lipid membrane in Gram positive bacteria may increase their susceptibility of penetration of antimicrobials and cell damage $(21,33$, 34).

Different solvents were used for the extraction process in order to enhance the antimicrobial potential of the algal extract. In this study chloroform and ethyl acetate mediated extracts showed the highest activity against tested microbial pathogens which was in accordance with the results from Bhagavathy et al., (33). They used several solvents to extract antimicrobial compounds from C. humicola, and showed antimicrobial activity of the extract depends on the extraction solvent. In addition, similar to our study, they showed chloroform and ethyl acetate mediated extracts had the highest antimicrobial potential.

The chemical nature and the polarity of the solvents used in the extraction process determine the extraction yield and composition of the extract and thus the biological activity. The difference in antimicrobial activity of different solvent mediated extracts could be attributed to the degree of polarity of algal bioactive compounds which determines their solubility in extraction solvents and extraction efficacy. The importance of using multiple solvents has been highlighted in biological screenings of microalgae (31, 35 ) and the bioactivities being largely dependent on the characteristics of the extraction solvent and the corresponding solubility of specific chemicals.

\section{Conclusion}

In conclusion, $C$. vulgaris showed moderate to high antimicrobial activity which could be influenced by growth condition and extraction solvents. Heterotrophic and mixotrophic growth significantly increased antimicrobial activity. In addition, chloroform mediated extract the highest antimicrobial potential was observed when chloroform was used as extraction solvent.

\section{Acknowledgments}

The authors would like to thank University of Guilan for providing facilities to carry out this work. providing necessary facilities for conducting the research.

\section{Conflict of Interest}

The authors declare that they have no conflict of interest. 


\section{References}

1. Perry JJ, Staley JT, Lory S. Microbial Life. Sinauer Associates Inc. 800 P, 2002.

2. Mala R, Sarojini M, Saravanababu S, Umadevi G. Screening for antimicrobial activity of crude extracts of Spirulina platensis. J Cell Tissue Res 2009; 9:1951-5.

3. Mashjoor S, Yousefzadi M, Esmaeili MA, Rafiee R. Cytotoxicity and antimicrobial activity of marine macro algae (Dictyotaceae and Ulvaceae) from the Persian Gulf. Cytotechnology 2015;1:10.

4. Ibanez E, Herrero M, Mendiola JA, Castro-Puyana M. Extraction and characterization of bioactive compounds with health benefits from marine resources: macro and micro algae, cyanobacteria, and invertebrates. In: HayesM (ed) Marine bioactive compounds, sources, characterization and applications. Springer, US, pp 55-98. 2012.

5. Mtolera MSP, Semesi AK. Antimicrobial activity of extracts from six green algae from Tanzania. Curr Trends In Marine Botanic Res East Afric Reg 1996; 211-7.

6. Tuney I, Cadirci BH, Unal D, Sukatar A. In: antimicrobial activities of crude extracts of marýne algae from the coast of Izmir (Turkey). Fresenius Environ Bull 2007;16:42834.

7. Ip PF, Chen F. Production of astaxanthin by the green microalga Chlorella zofingiensis in the dark. Process Biochem 2005;40:733-8.

8. Sun N, Wang Y, Li YT, Huang JC, Chen F. Sugar-based growth, astaxanthin accumulation and carotenogenic transcription of heterotrophic Chlorella zofingiensis (Chlorophyta). Process Biochem 2008;43:1288-92.

9. Liang Y, Sarkany N, Cui Y. Biomass and lipid productivities of Chlorella vulgaris under autotrophic, heterotrophic and mixotrophic growth conditions. Biotechnol lett 2009;31:1043-9.

10. Pratt R, Daniels TC, Eiler JB, Gunnison JB, Kumler WD. Chlorellin, an antibacterial substance from Chlorella. Science 1944; 99:351-2.

11. Taskin E, Ozturk E, Kurt O. Antibacterial activities of some marine algae from the Aegean Sea (Turkey). Afr J Biotechnol 2007;6:2746-51.

12. Chu WL. Biotechnological applications of microalgae. Int J Sci Med Edu 2012;6:24-37.

13. Wegmann TG, Hellstrom I, Hellstrom KE. Immunological tolerance: "Forbidden clones" allowed in tetraparental mice". Proc Natl Acad Sci U S A 1971;68:16447.

14. Clinical, and Laboratory Standard Institute (CLSI). Performance standards for antimicrobial disk susceptibility testing: approved standard: National Committee for Clinical Laboratory Standards 2012;29: 176.

15. Lalitha MK. Manual on antimicrobial susceptibility testing. Performance standards for antimicrobial testing: Twelfth Informational Supplement 2004;56238:454-6..
16. Bligh EG, Dyer WJ. A rapid method of total lipid extraction and purification. Can J Biochem Physiol 1959;37:911-7.

17. Singh P, Guldhe A, Kumari S, Rawat I, Bux F. Investigation of combined effect of nitrogen, phosphorus and iron on lipid productivity of microalgae Ankistrodesmus falcatus KJ671624 using response surface methodology. Biochemic Engin J 2015;94:22-9.

18. Chojnacka K, Marquez-Rocha FJ. Kinetic and stoichiometric relationships of the energy and carbon metabolism in the culture of microalgae. Biotechnol 2004;3:21-34.

19. Mata TM, Martins AA, Caetano NS. Microalgae for biodiesel production and other applications: a review. Renew. Sustain Energ Rev 2010;14 21732.

20. Varfolomeev SD, Wasserman LA. Microalgae as source of biofuel, food, fodder, and medicines. Appl biochem microbiol 2011;47:789-807.

21. Prashantkumar P, Angadi SB, Vidyasagar GM. Antimicrobial activity of blue-green and green algae. Ind J Pharm Sci 2006;68:647-8.

22. Najdenski HM, Gigova LG, Iliev II, Pilarski PS, Lukavsky J, Tsvetkova IV, et al. Antibacterial and antifungal activities of selected microalgae and cyanobacteria. Int J Food Sci Technol 2013;48:1533-40.

23. Sanmukh S, Bruno B, Ramakrishnan U, Khairnar K, Swaminathan S, Paunikar W. Bioactive compounds derived from microalgae showing antimicrobial activities. J Aquac Res Dev 2014;5:1-4.

24. Syed S, Arasu A, Ponnuswamy I. The Uses of Chlorella Vulgaris as Antimicrobial Agent and as a Diet: the Presence of Bio-active Compounds which caters the Vitamins, Minerals in General. Int J BioSci BioTechnol 2015;7:185-190.

25. Li XF, Xu H, Wu QY. Large-scale biodiesel production from microalga Chlorella protothecoides through heterotrophic cultivation in bioreactors. Biotechnol Bioengin 2007; 98:764-71.

26. Yeh KL, Chang JS. Effects of cultivation conditions and media composition on cell growth and lipid productivity of indigenous microalga Chlorella vulgaris ESP-31. Bioresource technol 2012;105:120-7.

27. Heredia-Arroyo T, Wei W, Hu B. Oil accumulation via heterotrophic/mixotrophic Chlorella protothecoides. Appl Biochem Biotechnol 2010;162:1978-95.

28. Heredia-Arroyo T, Wei W, Ruan R, Hu B. Mixotrophic cultivation of Chlorella vulgaris and its potential application for the oil accumulation from non-sugar materials. Biomass Bioenerg 2011;35:2245-53.

29. Desbois AP, Mearns-Spragg A, Smith VJ. A Fatty Acid from the Diatom Phaeodactylum tricornutum is Antibacterial Against Diverse Bacteria Including Multiresistant Staphylococcus aureus (MRSA). Marine Biotechnol 2009;11:45-52.

30. Priya S. Analysis of value-added biochemical compounds and antimicrobial activity of green algae Chlorella 
vulgaris. J Chem Pharm Res 2012;4:2577-9.

31. Jayshree A, Jayashree S, Thangaraju N. Phytochemical Screening and Antimicrobial Activity of Chlorella Vulgaris Beijerinck. Int J Curr Res Rev 2012;4:33-8.

32. Ghasemi Y, Moradian A, Mohagheghzadeh A, Shokravi S, Morowvat MH. Antifungal and antibacterial activity of the microalgae collected from paddy fields of Iran: characterization of antimicrobial activity of Chlorococcus dispersus. J Biol Sci 2007;7:904-10.

33. Bhagavathy S, Sumathi $P$ and Bell IJS. Green algae Chlorococcum humicola-a new source of bioactive compounds with antimicrobial activity. Asian Pac J Trop Biomed 2011;1:1-7.
34. Ordog V, Stirk R, enobel M, Bancirova M, Strand J, Vanstanden E. Screening microalgae for some potentially useful agricultural and pharmaceutical secondary metabolites. J Appl phycol 2004;16:309-14.

35. Nair BB, Krishnika A. Antibacterial activity of freshwater Microalga (Sc e ne de sm us sp.) against three bacterial strains. J Biosci Res 2011;2:160-5. 